\title{
El discurso religioso presente en la narrativa contemporánea como formador de identidad
}

\section{Religious discourse in contemporary narrative in identity shaping}

María Ángela Sánchez Quirós

Colegio Humanístico Costarricense, Universidad Nacional

Costa Rica

msq012@gmail.com

\begin{abstract}
Resumen
La tradicional cultura patriarcal heredada por la religión católica se hace evidente en la literatura contemporánea de Latinoamérica, principalmente en textos escritos por mujeres, en cuyos discursos se refleja una fuerte influencia religiosa que determina el actuar $\mathrm{y}$ pensar de los personajes femeninos y masculinos que en ellas se configuran. Hacia mediados del siglo XX la narrativa latinoamericana empezó a mostrar situaciones de inconformidad social en cuanto a la forma en la que se vivía y se transmitía el género en los discursos literarios, ya que se encontraba plagado de prejuicios heredados de la tradición religiosa occidental, los cuales oprimían cada vez más a la mujer, mientras otorgaban poder al masculino y claramente invisibilizaban otras formas de sexualidad. Ante esta situación surgen talentos femeninos en el ámbito literario que logran reflejar esta inconformidad y cuestionar los valores patriarcales, generando nuevas e innovadoras visiones de mundo más incluyentes, justas y equitativas.
\end{abstract}

Palabras claves: género, discurso, religión, literatura. 


\begin{abstract}
The patriarchal tradition inherited by the Roman Catholic religion is evidented in the contemporary literature in Latin America mainly in texts written by women, in which speeches influenced by a strong religious you can determiny the way of acting and thinking of female and male. Toward the middle of XX century latinamerican literature started to evidence social discomfort about the way gender was "lived" and transmited in their speeches which was full of inherited prejudice of occidental religious traditions that oppressed women and other sexual preferences while males become more and more powerfull. Next to this amazing situation female talent arises with questioning about patriarchal values discomfort generating new ways of view of the world, more inclusive and fair.
\end{abstract}

Keywords: gender, speech, religion, literature.

$\mathrm{L}$ a sociedad actual en la cual convivimos ha sido construida sobre bases muy cuestionables de sistemas injustos, opresores y manipuladores. La forma como se ha distribuido el poder en las sociedades latinoamericanas ha sido excluyente, elitista y desigual. La narrativa contemporánea refleja esto a través de sus metáforas, las cuales son construidas con un gran nivel de sarcasmo, lo cual evidencia un sentimiento de impotencia ante tan irremediable realidad.

Uno de los temas que comprueba la injusta realidad en la que vivimos ha sido y seguirá siendo el de género. Este ha sido ampliamente abordado por diversas áreas del conocimiento. La sociología, la psicología, la etnografía, incluso la teología se ha encargado de dar enfoques nuevos y aportes relevantes al tema. El exhaustivo tratamiento que se ha brindado al género, sin embargo, ha sido el detonante de múltiples teorías que hoy tratan de explicar la gran cantidad de identidades sexuales que conviven en un mundo plagado de homofobia e ignorancia. Entre ellas podemos citar la teoría feminista de autoras como Lagarde, Shussler y Guevara, así como la teoría queer, de autoras como Butler, Louro, entre otras.

La información procedente de investigaciones, estudios o bien de nuestra propia experiencia es insuficiente para conformar un mundo con mayor equidad, solidaridad y sororidad. Más bien pareciera que cuanto más se aborda el tema, más temor se experimenta al observar la otredad de género.

Si partimos de un enfoque humanista del mundo, un pilar básico, inherente y convergente ha de ser la equidad de género. 
Ivonne Guevara (2002) ofrece una definición del concepto de género desde una perspectiva hermenéutico - teológica. Para ella el género no es un hecho solamente biológico, sino que abarca lo cultural; es decir, la identidad que ha sido socialmente establecida para cada uno de los sexos, a través de métodos de sometimiento de unos sujetos a otros. Desde esta perspectiva, se puede decir que existe una relación de poder que engendra relaciones humanas basadas en la desigualdad e inequidad.

Desde un enfoque humanista -es decir, integral, equitativo, solidario y que fomenta la participación inclusiva de todos y todas- estas diferencias no pueden ser invisibilizadas o excluidas de la realidad social cotidiana, pues esto sería incoherente con la práctica humanista y con los principios que el Humanismo propugna.

Sin embargo, resulta contradictorio hablar de equidad en una sociedad de tradición patriarcal como la nuestra. El sistema que rige el mundo en el cual vivimos fomenta la desigualdad de género en todas las áreas de la vida cotidiana, mientras legitima prácticas opresoras y marginadoras de géneros diferentes al masculino. Incluso, los hombres sufren de opresión al exigírseles actuar de forma "masculina", es decir: fuerte, grotesca, insensible.

La literatura no escapa de esta realidad, sino que como es su obligación, la denuncia de múltiples maneras a través de la construcción de personajes contradictorios, rebeldes o irracionales. Un ejemplo es el famoso cuento "Valle Alto" de Yolanda Oreamuno, el cual ha sido analizado mucho por su gran contenido erótico y por la novedad de ser escrito por una mujer en una época caracterizada por la opresión del patriarcado. Sin embargo, existen una serie de señales que indican la gran contradicción experimentada por quien narra, cuando se refiere a la corporalidad:

El hombre se había quitado el saco y tirado hacia atrás el cuello de la camisa (...) Y allí los ojos se quedaron. Y junto a ellos cayó el juicio primero, la observación luego y la sensación después.

El juicio dijo: "Es un cuello fuerte". Y eso fue todo.

La observación dijo: "Debajo de esa piel gruesa, de color moreno, un poco rojo, se mueven fuertes tendones y juegan fieros músculos. La impresión de fuerza no la da ciertamente, el tamaño de ese cuello, casi algo corto, sino su rectitud, su dureza, su obediencia elástica a los movimientos de la cabeza o los hombros, su anchura cortada paralela con la base de las orejas, la sangre rica que se mira correr bajo la piel."

Y la emoción dijo: "Ha de tener una dureza consoladora ese cuello al tacto. Ha de 
ser estupendo sentir bajo los dedos la tensión de los músculos jugar escurridiza. Y la piel estará reacia, joven tibia."

$\mathrm{Y}$ entonces, cuando ya la emoción estaba al borde de la aventura, advino el razonamiento: “¿Pero es que yo también me he de dejar dominar por la embriaguez de este clima? (Oreamuno, 1999, p.153)

Del fragmento anterior, es posible extraer una serie de elementos que remiten al discurso de género presente en la sociedad patriarcal:

- Corporalidad: la mujer describe el cuerpo del hombre desde un enfoque erótico, así como el deseo de que su cuerpo sea alcanzado por él

- Masculinidad: ligada a lo fuerte (de hecho el término se repite varias veces en el fragmento), la grandeza, lo enérgico

- Lo femenino: la negación del deseo, la necesidad de mantener una actitud de pudor frente al varón que tiene enfrente

- La razón: relacionada con la necesidad de hacer "lo correcto" o lo que socialmente se considera "bueno"; de lo contrario, actuaría sin raciocinio, es decir, sin reglas, sin normas, sin juicio, locamente

En este punto emerge el discurso religioso, pues en una sociedad de tradición patriarcal, lo correcto es aquello concordante con los valores morales que la religión aprueba. Sin embargo, la expresión de la sexualidad ha sido negada para la mujer desde María y condenada desde Eva. Por tanto, la mujer que decide desprenderse de esos prejuicios es excluida, marginada y condenada a la locura.

Un melancólico razonamiento que la molestaba, hoy como nunca antes, había vuelto a su conciencia. Ese razonamiento le prohibía, y le prohibiría siempre, preguntar en qué forma había llegado, y tendría que llevar definitivamente aquella espantosa laguna de la memoria con que despertara. (Oreamuno, 1999, p.166)

Otro texto que se refiere al tema de género mediante un discurso religioso es el de Isabel Allende, "Boca de sapo", el cual describe a una trabajadora del sexo, quien a pesar de su vocación, vive una historia de amor con un trabajador de la Compañía Ganadera, tan intensa como las historias de príncipes y princesas.

Hermelinda, en cambio, era una hembra cercana y precisa, con una atrevida mezcla de sangre en las venas y muy buena disposición para festejar. Había escogido ese oficio de consuelo por pura y simple vocación, le gustaban casi todos los hombres en general y muchos en particular.

(...) 
Hermelinda ni el extranjero aparecieron. Transcurrieron tres horas, cuatro, toda la noche, amaneció y sonaron las campanas de la gerencia llamando al trabajo, sin que se abriera la puerta.

Al mediodía los amantes salieron del cuarto. Pablo no cruzó ni una mirada con nadie, partió a ensillar su caballo, otro para Hermelinda y una mula para cargar el equipaje. La mujer vestía pantalón y chaqueta de viaje y llevaba una bolsa de lona repleta de monedas atada a la cintura. Había una nueva expresión en sus ojos y un bamboleo satisfecho en su trasero memorable. Ambos acomodaron con parsimonia los bártulos en el lomo de los animales, se subieron a los caballos y echaron a andar. Hermelinda hizo una vaga señal de despedida a sus desolados admiradores y siguió a Pablo, el asturiano, por las llanuras peladas, sin mirar hacia atrás. Nunca más regresó. (Allende. 1989, p. 38)

En este texto existe una sentencia moral implícita, pues lo que Hermelinda hacía está incorrecto y por eso debe llegar un hombre a salvarla de tan desagradable labor. De nuevo se reproducen los esquemas del hombre fuerte, guapo, salvador de la mujer incapaz de salvarse por sus propios medios. O bien la mujer carente de raciocinio, pero que sirve para tener sexo, ya que la gran cantidad de hombres del pueblo tienen derecho a satisfacer sus deseos sexuales.

Un análisis del discurso religioso en torno al género podría realizarse sobre cualquier texto narrativo latinoamericano, pues la tradición patriarcal y cultural que nos caracteriza ha reprimido lo no- masculino, de esta forma la literatura se ha convertido en el medio más eficaz de denuncia y expresión social acerca del tema.

Al observar con detenimiento la narrativa contemporánea, se evidencia la parte humana de la sociedad, sus contradicciones, sus necesidades, las represiones de las que ha sido víctima, los deseos, los sueños. Al profundizar en esto se pretende sensibilizar al ser humano, así como promover espacios de reflexión y autocrítica para formar personas más solidarias, integrales y críticas con su entorno.

\section{Referencias}

Allende, I. (1989) Los cuentos de Eva Luna. Recuperado de http://biblioteca.mygeocom. com/index.php/wpfb-file/isabel-allende-los-cuentos-de-eva-luna-pdf/, 04 julio 2014

Althus Reid, M. (2000). Una teología indecente. Barcelona: Ediciones Bellaterra, S. L. http://dx.doi.org/10.4324/9780203468951 
Butler, J. (1956). El género en disputa: el feminismo y la subversión de la identidad. Madrid: Paidós.

Butler, J. (1956). Cuerpos que importan. Madrid: Paidós.

Foucault, M. (2011). El orden del discurso. Barcelona: TusQuets.

Guevara, I. (2002). El rostro oculto del mal. Una teología desde la experiencia de las mujeres. Madrid: Editorial Trotta.

Lagarde, M. (2001). Claves feministas para la negociación en el amor. Managua: Puntos de encuentro. Managua, Nicaragua.

Oreamuno, Y. (1999) Relatos escogidos. San José: Editorial Costa Rica.

Schussler Fiorenza, E. (2000). Cristología feminista crítica. Jesús hijo de Miriam, Profeta de la sabiduría. Madrid: Trotta, S.A. Madrid. 